\title{
How should Helicobacter pylori negative patients be managed?
}

\author{
V Stanghellini, C Tosetti, R De Giorgio, G Barbara, B Salvioli, R Corinaldesi
}

\section{Department of \\ Internal Medicine and Gastroenterology, University of Bologna, Policlinico S. Orsola-Malpighi, Via Massarenti 9, 40138 \\ Bologna, Italy V Stanghellini C Tosetti R De Giorgio G Barbara B Salvioli R Corinaldesi \\ Correspondence to: Professor Stanghellini.}

\begin{abstract}
Summary
Dyspepsia is a digestive syndrome distinct from (although frequently overlapping with) gastrooesophageal reflux disease (GORD) and irritable bowel syndrome (IBS), which is characterised by various combinations of painful and non-painful symptoms arising from the epigastrium. Dyspepsia can be secondary to a variety of diseases, but in most instances it is idiopathic. Helicobacter pylori infection is responsible for the majority of peptic ulcers and of other diseases potentially associated with dyspepsia. Nevertheless, a causal role for $H$ pylori infection in symptom occurrence has not been established. Experimental data indicate that $H$ pylori eradication does not improve symptoms in the majority of dyspeptic patients. It has been proposed recently that $H$ pylori negative patients should be managed according to their clinical presentation. Some reports suggest that taking into consideration the most relevant or "predominant" symptom may help to identify distinct subgroups among dyspeptic patients with different underlying pathophysiological abnormalities and different responses to treatment. Well designed and conducted prospective studies are needed to verify whether treatment of $H$ pylori negative dyspeptic patients based on the predominant symptom actually is a cost effective approach.
\end{abstract}

\section{Introduction}

Doctors and investigators have been puzzled by dyspepsia for decades. Two factors have recently occurred to stimulate further their interest in this field: understanding of the pathogenic role played by $H$ pylori in gastroduodenal diseases potentially associated

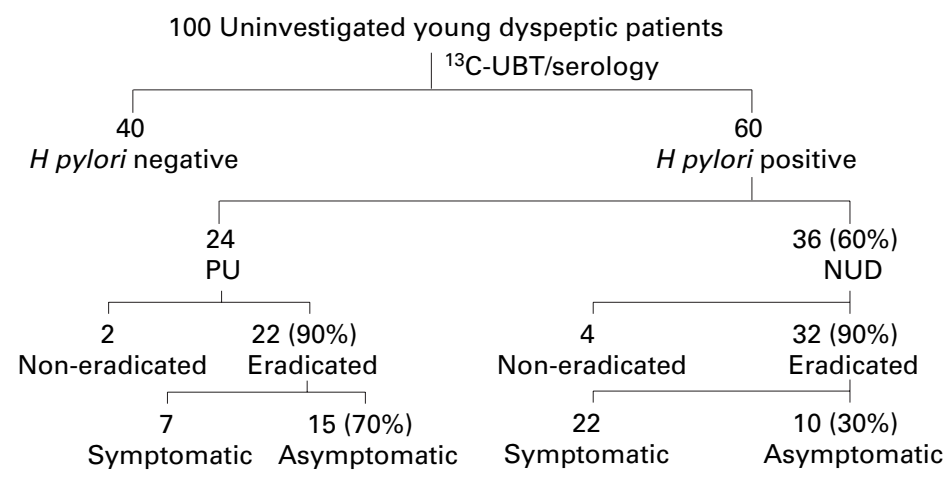

with dyspeptic symptoms; and the squeeze on health care budgets which prompts scrutiny of diagnostic and therapeutic decisions.

Organic diseases are rare among young $H$ pylori negative dyspeptic patients without alarm features ${ }^{1}$ and non-invasive $H$ pylori testing has been proposed to decrease referrals for upper gastrointestinal endoscopy without significantly increasing the risk of missing dangerous diseases. ${ }^{2-4}$ Both European ${ }^{5}$ and North American guidelines ${ }^{6}$ suggest that all young patients who are found to be $H$ pylori positive by breath test or serology should be treated, whereas endoscopy should be performed only in patients with alarm features or nonresponders to treatment. Young $H$ pylori negative patients should be treated with antisecretory drugs or prokinetic agents. ${ }^{7}$

If $H$ pylori plays a pathogenic role in the production of dyspeptic symptoms, a large scale eradication strategy should be associated with a remarkable decrease in dyspepsia in the population, but this does not seem to be the case. Despite effective healing of ulcer craters, $H$ pylori eradication fails to control dyspeptic symptoms in over $30 \%$ of patients with ulcers, ${ }^{8}$ and the effect of $H$ pylori eradication on symptoms in patients with functional dyspepsia is even more disappointing. Unfortunately, many of the available eradication studies are flawed and therefore are difficult to interpret. ${ }^{9}$ Even the most recent studies with appropriate follow up periods have produced conflicting results: patients with symptom improvement after $H$ pylori eradication ranging between $0 \%{ }^{10}$ and $86 \% .{ }^{11}$ Furthermore, recent evidence suggests that $H$ pylori might be associated with the onset of GORD, ${ }^{12}$ although conflicting results have also been published. ${ }^{13}$ Altogether these figures indicate that approximately $70 \%$ of young patients with uninvestigated dyspepsia would remain symptomatic if a large scale eradication programme was undertaken (fig 1). Management of dyspepsia, therefore, will be largely independent of the $H$ pylori status of affected individuals. We propose a hypothetical management strategy based mainly on clinical features and summarise the current literature that may substantiate the proposed plan.

\section{Management of $\mathrm{H}$ pylori negative patients}

Figure 2 shows a hypothetical algorithm for the management of uninvestigated dyspepsia. Factors other than $H$ pylori status should initially guide clinical decisions. Patients with late onset

Abbreviations used in this paper: GORD, gastro-oesophageal reflux disease; IBS, irritable bowel syndrome. 


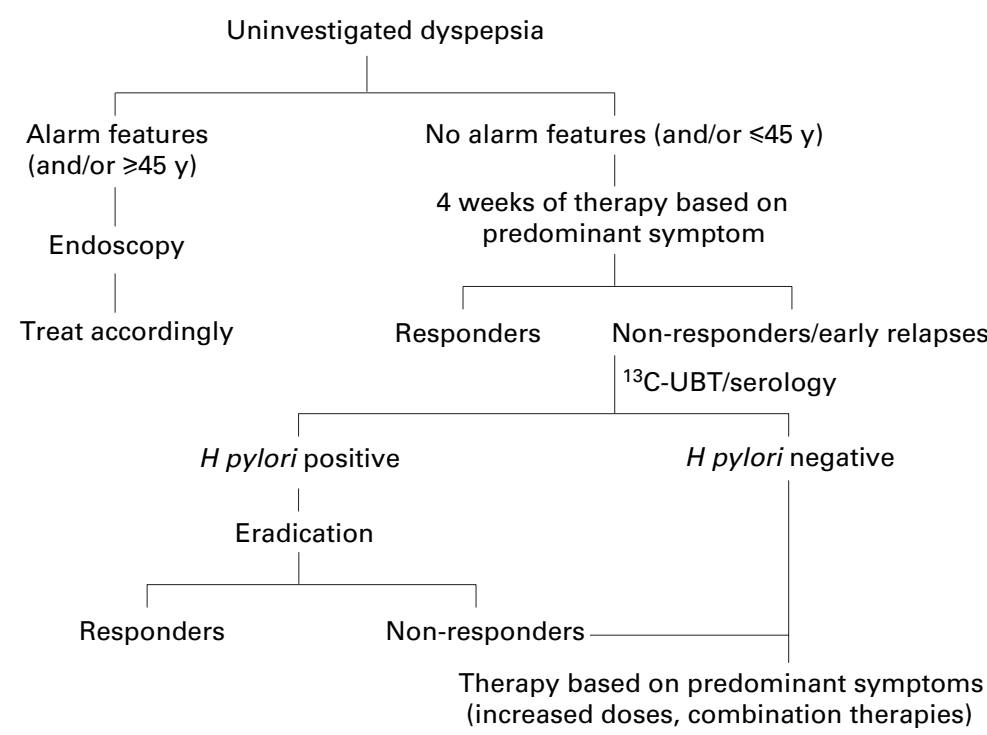

Figure 2 Management of uninvestigated dyspepsia. Short courses of medical treatment tailored to the predominant symptom should be prescribed initially. H pylori investigation and treatment of infected individuals should be considered for non-responders or in the case of frequent recurrences. UBT, urea breath test.

of symptoms and/or associated alarm features should be investigated immediately. The remainder, with a low probability of having an organic disease, ${ }^{1}$ should be treated symptomatically. In those who fail to respond or have frequent relapses, $H$ pylori testing followed by eradication in infected cases may be considered. If patients do not think that a serious disease-for example, cancer, is the cause of their symptoms, non-invasive diagnostic tests should performed.

Three different types of $H$ pylori negative dyspeptic patients can therefore be encountered in clinical practice:

- dyspeptic patients with no evidence of $H$ pylori infection on non-invasive testing;

- dyspeptic patients with no evidence of $H$ pylori infection at endoscopy; and

- dyspeptic patients with no evidence of $H$ pylori infection after successful eradication. As previously mentioned, there is a substantial overlap between the first two groups among young individuals, as organic diseases are rare in these subjects. ${ }^{1}$ The third group may be more difficult to manage as patients may be frustrated by the experience of an unsuccessful therapeutic attempt to control their symptoms and by the objective evidence that the infection of their stomach was not the cause of their symptoms.

$H$ pylori negative patients with chronic dyspepsia should be given short courses of medical treatment. Increasing evidence suggests that the choice of drug should be tailored to the clinical presentation, ${ }^{7}$ and more specifically to the predominant symptom(s). ${ }^{14}$ The validity of these guidelines relies on the hypothesis that the presence of a predominant symptom may help to identify dyspepsia subgroups characterised by distinct underlying pathophysiological mechanisms.

Indeed, many of the symptoms included in the definition of dyspepsia are intuitively suggestive of different pathogenic mechanisms and the existence of distinct dyspepsia subgroups is already considered clinically useful by general practitioners. ${ }^{15}$ Three working teams proposed definitions of dyspepsia subgroups with the endorsement of international experts in the field. ${ }^{16-18}$ It is now generally accepted that dyspepsia is different from GORD and IBS, ${ }^{17}{ }^{18}$ and that two main hypothetical subgroups can be identified ${ }^{16-18}$ : ulcer-like and dysmotilitylike. The former is characterised by several aspects of pain, the latter by distinct symptoms different from pain and suggestive of impaired gastroduodenal motility. None of these reports recommened investigation of the severity of symptoms. Investigating the presence or absence of symptoms without quantitating their severity may decrease the power of a symptom questionnaire, as digestive symptoms are very frequent in the general population and among individuals who do not seek medical help. ${ }^{19}$ Adopting these criteria Talley and colleagues ${ }^{20}$ failed to detect any difference among dyspeptic subgroups at upper gastrointestinal endoscopy.

Conversely, some data are available to support the validity of a classification which takes into account the severity of symptoms. Talley et al reported that low dose omeprazole is superior to placebo in controlling symptoms in patients with ulcer-like dyspepsia, provided that this subgroup is identified by predominant epigastric pain. ${ }^{21}$ Cisapride has been reported to be particularly efficacious in controlling symptoms of patients with delayed gastric emptying ${ }^{22}$ whose predominant complaint is discomfort. ${ }^{23}{ }^{24} \mathrm{~A}$ theoretical economic model, ${ }^{25}$ supported by experimental evidence, ${ }^{26}$ suggested that identification of a predominant symptom may provide significant benefits and effective resource saving in the management of dyspeptic patients. Well designed and conducted studies are needed to confirm the validity of this hypothesis.

\section{Do $H$ pylori infected and uninfectd dyspeptic patients respond differently to symptomatic treatment?}

Due to the scarce (if any) symptomatic effect of $H$ pylori eradication, one may anticipate that treatment of dyspepsia should be unrelated to $H$ pylori status. Whether $H$ pylori negative and positive dyspeptic patients respond differently to symptomatic treatment has not been properly investigated. We will briefly compare demographic, pathophysiological, and clinical features of the two subgroups.

\section{DEMOGRAPHIC FEATURES}

When using non-invasive tests to identify $H$ pylori status, infected and uninfected dyspeptic patients show very similar demogarphic features. Both groups are characterised by the prevalence of male sex and have similar smoking and eating habits; $H$ pylori negative patients, however, are younger, more frequently involved in non-manual working activities, and less often have a positive family history of peptic ulcer disease. ${ }^{27} 28$ 
PATHOPHYSIOLOGICAL FEATURES

$H$ pylori/gastric acid hypersecretion

The role of acid in the development of dyspeptic symptoms has not been clarified. Both basal and pentagastrin stimulated acid secretion are normal in patients with functional dyspepsia, regardless of their $H$ pylori status. ${ }^{29}$ Conversely, patients with $H$ pylori infection and otherwise unexplained dyspepsia have gastrin releasing peptide stimulated gastric acid secretion that is lower than that of $H$ pylori positive patients with duodenal ulcer, but higher than in $\mathrm{H}$ pylori negative controls. ${ }^{30}$

H pylori/gut dysmotility

Gastrointestinal dysmotility is a complex function characterised by myoelectrical smooth muscle activity, movement of the gut wall, intraluminal phasic and tonic pressure changes, and movement of intraluminal contents. No single technique is available to measure all of these events simultaneously and we have only fragmentary information both in health and disease. Regardless of the technique adopted, gastroduodenal motor abnormalities have been detected in the vast majority of studies on functional dyspepsia. ${ }^{31}$ Nevertheless, their relation with symptoms and $H$ pylori infection has only been partially explored. Testoni et al manometrically recorded decreased fasting and postprandial antral motility in $H$ pylori infected dyspeptic patients, compared with both healthy controls and $H$ pylori negative patients, ${ }^{32}$ but this motor abnormality was not modified by $H$ pylori eradication. ${ }^{33}$ Pieramico and colleagues ${ }^{34}$ confirmed previous data $^{31}$ by showing lower antral contractile activity in dyspeptic patients and failed to detect significant differences between $\mathrm{H}$ pylori positive and negative patients, but reported normalisation of interdigestive motility in $H$ pylori positive patients after eradication. In keeping with these findings, preliminary data ${ }^{34}$ reported increased antral contractility after eradication. Several studies investigating scintigraphic gastric emptying and $H$ pylori status failed to detect any difference in gastric motility between $H$ pylori positive and negative dyspeptic patients. However, recent studies done using appropriate methods, showed a higher prevalence of motility disturbances among uninfected patients. ${ }^{28} 3536$ Indeed, these two putative mechanisms of dyspepsia do not seem to interact as $H$ pylori eradication does not influence gastric emptying. ${ }^{37-39}$

\section{H pylori/hypersensitivity}

Dyspeptic patients as a group have gastric ${ }^{40}{ }^{41}$ and duodenal ${ }^{42}$ hypersensitivity which is not influenced by sex or age. ${ }^{40}$ The gut wall contains three kinds of neural receptors: chemoreceptors, in the mucosa, which respond to chemical stimuli; mechanoreceptors, in the smooth muscle layer, which respond to stretch or compression; and nociceptors, the most numerous receptors, which are commonly silent, but can be "recruited" by any stimulus that is strong enough to induce pain. ${ }^{43} \mathrm{H}$ pylori infection has not been shown to be involved in the aetiology of gastric ${ }^{41}$ or duodenal hypersensitivity ${ }^{42}$ in patients with functional dyspepsia.

\section{CLINICAL FEATURES}

Whether $H$ pylori negative patients have a peculiar symptom profile has not been established yet. A low prevalence of $H$ pylori was observed in a group of patients with strictly selected functional dyspepsia whose predominant symptom was postprandial fullness. ${ }^{28}$ In keeping with these findings, epigastric pain and heartburn were the symptoms most frequently associated with $H$ pylori infection, as detected by breath test ${ }^{44}$ or serology ${ }^{45}$ in separate studies from Northern Italy, whereas the prevalence of infection in subjects complaining of postprandial fullness was lower and similar to that of asymptomatic subjects. Histological $H$ pylori status, gastric acid secretion, gastrin concentrations, cutaneous electrogastrography, and gastric emptying were evaluated in 144 Japanese patients with functional dyspepsia. ${ }^{46}$ All the parameters were similar among the dyspepsia subgroups, with the exception of gastric emptying which was more frequently delayed in patients with dysmotility-like and reflux-like dyspepsia, whereas no association was detected between $H$ pylori and symptoms. Hovelius et al explored the relation between serologically evaluated $H$ pylori status and dyspeptic symptoms among patients seen by general practitioners in Sweden. $H$ pylori positive patients presented with ulcer-like symptom scores significantly higher than $H$ pylori negative patients. ${ }^{27}$

\section{Conclusions}

$H$ pylori infection certainly plays a limited role in symptom generation in patients with functional dyspepsia and, therefore, treatments other than $H$ pylori eradication are needed to control dyspeptic symptoms in most patients. It has been proposed that dysmotility-like dyspepsia should be distinguished from the ulcerlike form according to the predominant symptom, and that the two subgroups should be treated with prokinetic agents and antisecretory drugs, respectively. The validity and cost effectiveness of this hypothesis have still to be explored fully. Furthermore, it is necessary to clarify whether and to what extent $H$ pylori negative and positive patients respond differently to symptomatic treatment. Nevertheless, testing for and treatment of $\mathrm{H}$ pylori infection is a possible option in patients who fail to respond to appropriate courses of symptomatic treatment or who have heard of the "bug" and want to get rid of it.

1 McColl KEL, El-Nujumi A, Murray L, et al. The Helicobacter pylori breath test: a surrogate marker for pepic ulcer disease in dyspeptic patients. Gut 1997;40:302-6.

2 Hallissey MT, Allum WH, Jewkes AJ, et al. Early detection of gastric cancer. BMF 1990;30:513-15.

3 Sobala GM, Crabtree JE, Penrith JA, et al. Screening dyspepsia by serology to Helicobacter pylori. Lancet 1991; 338:94-6.

4 Patel P, Khulusi S, Mendall MA, et al. Prospective screening of dyspeptic patients by Helicobacter pylori serology. Lancet 1995;346:1315-18.

5 The European Helicobacter Pylori Study Group. Current European concepts in the management of Helicobacter pylori infection. The Maastricht Consensus Report. Gut 1997;41:8-13. 
6 Talley NJ, Silverstein MD, Agreus L, et al. AGA Technical review: evaluation of dyspepsia. Gastroenterology 1998;114 review: eval.

7 Fisher RS, Parkman HP. Management of nonulcer dyspepsia. N Engl f Med 1998;339:1376-81.

8 Bretagne JF, Caekaert A, Barthelemy P. The course of symptoms after eradication of Helicobacter pylori: a one-year follow-up of a cohort of 258 patients with duodenal ulcer or nonulcer dyspepsia [abstract]. Gastroenterology 1998;114:A81.

9 Talley NJ. A critique of therapeutic trials in Helicobacter pylori-positive functional dyspepsia. Gastroenterology 1994 106:1174-83.

10 Di Mario F, Dal Bò N, Salandin S, et al. Helicobacter pylori eradication in functional dyspepsia: a prospective randomized 3 year study [abstract]. Gastroenterology 1998;114: A104.

11 McCarthy C, Patchett S, Collins RM, et al. Long-term prospective study of Helicobacter pylori in nonulcer dyspepsia. Dig Dis Sci 1995;40:114-19.

12 Labenz J, Blum AL, Bayerdorffer E, et al. Curing Helicobacter pylori infection in patients with duodenal ulcer may provoke reflux esophagitis. Gastroenterology $1997 ; 112: 1442-7$

13 Talley NJ, Janssens J, Lauritsen K, et al. No increase of reflux symptoms or esophagitis in patients with non-ulcer dyspepsia 12 months after Helicobacter pylori eradication. A randomized double-blind placebo-controlled trial [abstract]. Gastroenterology 1998;114:A1250.

$14 \mathrm{Hu}$ WH, Talley NJ. Functional (non-ulcer) dyspepsia: unexplained but not unmanegeable. Med F Aust 1998;168 507-12.

15 Chiba N, Bernard L, O'Brien BJ, et al. A Canadian physician survey of dyspepsia management. Can $\mathcal{F}$ Gastroenterol 1998;12:83-90.

16 Colin-Jones DG, Bloom B, Bodemar G, et al. Management of dyspepsia: report of a working party. Lancet 1988;i: of dyspep

17 Drossman DA, Thompson WG, Talley NJ, et al. Identification of subgroups of functional gastrointestinal disorders. tion of subgroups of functional gastro

18 Talley NJ, Colin-Jones D, Koch KL, et al. Functional dyspepsia: a classification with guidelines for diagnosis and management. Gastroenterology Int 1991;4:145-60.

19 Jones R, Lydeard S. Prevalence of symptoms of dyspepsia in the community. BMF 1989;298:30-2.

20 Talley NJ, Weaver AL, Tesmer DL, et al. Lack of discriminant value of dyspepsia subgroups in patients referred for upper endoscopy. Gastroenterology 1993;105: $1378-86$

21 Talley NJ, Meineche-Schmidt V, Parè P, et al. Is acid suppression efficacious in non-ulcer dyspepsia? A double blind, randomised, controlled trial with omeprazole [abstract]. Gastroenterology 1998;114:A1244.

22 Jian R, Ducrot F, Ruskone A, et al. Symptomatic, radionuclide and therapeutic assessment of chronic idiopathic dyspepsia. A double-blind placebo-controlled evaluation of cisapride. Dig Dis Sci 1989;34:657-64.

23 Barnett JL, Behler EM, Appelman HD, et al. Campylobacter pylori is not associated with gastroparesis. Dig Dis bacter pylori is not a
Sci $1989 ; 34: 1677-80$

24 Stanghellini V, Tosetti C, Paternicò A, et al. Risk indicators of delayed gastric emptying of solids in 343 patients with functional dyspepsia. Gastroenterology 1996;110:1036-42.

25 Tosetti C, Stanghellini V. Management of dyspepsia in general practice: a critical assessment. Pharmacoeconomics 1998;14(suppl 2):57-66.

26 Haycox A, Butterworth M, Walley T, et al. Development of an economic model for the management of upper gastrointestinal disease in primary care. Preliminary findings. Pharmacoeconomics 1998;14(suppl 2):11-23.

27 Hovelius B, Andersson SI, Hagander B, et al. Dyspepsia in general practice and symptoms in relation to Helicobacter pylori serum antibodies. Scand $\mathcal{F}$ Gastroenterol 1994;29: 506-10.
28 Gasbarrini G, Pretolani S, Bonvicini F, et al. A population based study of Helicobacter pylori infection in a European country: the San Marino Study. Relations with gastrointestinal diseases. Gut 1995;36:838-44.

29 Tucci A, Corinaldesi R, Stanghellini V, et al. Helicobacter pylori infection and gastric function in patients with chronic idiopathic dyspepsia. Gastroenterology 1992;103: 768-74.

30 El-Omar E, Penman I, Ardill JE, et al. A substantial proportion of non-ulcer dyspepsia patients have the same abnormality of acid secretion as duodenal ulcer patients. Gut 1995;36:534-8

31 Stanghellini V, Ghidini C, Ricci Maccarini M, et al. Fasting and postprandial gastrointestinal motility in ulcer and nonulcer dyspepsia. Gut 1992;33:184-90.

32 Testoni PA, Bagnolo F, Colombo E, et al. The correlation in dyspeptic patients of Helicobacter pylori infection with changes in interdigestive gastroduodenal motility patterns but not in gastric emptying. Helicobacter 1996;1:229-37.

33 Bagnolo F, Testoni PA. In Helicobacter pylori-associated dyspepsia, interdigestive gastroduodenal motor pattern mproves with cisapride, but not with bacterial eradication [abstract]. Neurogastroenterol Motil 1998;10:436.

34 Pieramico O, Distchuneit $\mathrm{H}$, Malfertheiner P. Gastrointestinal motility in patients with non-ulcer dyspepsia: a role for Helicobacter pylori infection? Am $\mathcal{f}$ Gastroenterol 1993;88:364-8.

35 Thor P, Lorens K, Tabor S, et al. Dysfunction in gastric myoelectric and motor activity in Helicobacter pylori posimyoelectric and motor activity in Helicobacter pylori posiPharmacol 1996;47:469-76.

36 Scott AM, Kellow JE, Shuter B, et al. Intragastric distribution and gastric emptying of solids and liquids in functional dyspepsia. Lack of influence of symptom subgroups and H. pylori-associated gastritis. Dig Dis Sci 1993;38:2247-54

37 Su YC, Jan CM, Wang WM, et al. Does Helicobacter pylori infection play a role in the pathogenesis of non-ulcer dyspepsia - a study of gastric emptying time

38 Peitz U, Blaudszun S, Aygen S, et al. No significant change of delayed gastric emptying in functionally dyspeptic patients after cure of Helicobacter pylori [abstract]. Gastroenterology 1996;110:A733.

39 Parente F, Imbesi V, Maconi G, et al. Effects of Helicobacter pylori eradication on gastric functions indices in functional dyspepsia. A prospective controlled study. Scand $\mathcal{F}$ Gastroenterol 1998;33:461-7.

40 Lèmann $M$, Dederding JP, Flouriè $B$, et al. Abnormal perception of visceral pain in response to gastric distension in chronic idiopathic dyspepsia. The irritable stomach syndrome. Dig Dis Sci 1991;36:1249-54.

41 Mearin F, de Ribot X, Balboa A, et al. Does Helicobacter pylori infection increase gastric sensitivity in functional dyspepsia? Gut 1995;37:47-51.

42 Holtmann G, Talley NJ, Goebell H. Association between $\mathrm{H}$. pylori, duodenal mechanosensory thresholds, and small intestinal motility in chronic unexplained dyspepsia. Dig Dis Sci 1996;41:1285-91.

43 Mayer EA, Raybould HE. Role of visceral afferent mechanisms in functional bowel disorders. Gastroenterology mechanisms in function

44 Bazzoli F, Zagari RM, Festi D, et al. A population based study of Helicobacter pylori infection. III: Prevalence by ${ }^{13} \mathrm{C}$-urea breath test and association with dyspeptic symptoms [abstract]. Gut 1997;41(suppl 3):A106.

45 Trespi E, Broglia F, Villani L, et al. Distinct profiles of gastritis in dyspepsia subgroups. Their different clinical responses to gastrin healing after Helicobacter pylori eradication. Scand f Gastroenterol 1994;29:884-8.

46 Takayasu H, Harasawa S, Miwa T, et al. Investigation of gastric function and prevalence of Helicobacter pylori in nonulcer dyspepsia [in Japanese]. Fpn f Gastroenterol 1993;90: 743 . 